\title{
The Opening of the Cyclohexane Ring of Pinanones Using Baeyer-Villiger Conditions
}

\begin{abstract}
Alan F. Thomas* and Florence Rey
Abstract. Reaction of nopinone (1) with 3-chloroperbenzoic acid in $\mathrm{CHCl}_{3}$ leads, in a very slow reaction, to the two lactones 2 and 3 in the ratio $9: 1$. Methylnopinone (4) under the same conditions gives the homologous lactones 6 and 7, but in the reverse ratio, together with minor amounts of the stereoisomers 8 and 9 arising from the presence of a small amount of the trans-isomer in the starting material. For the successful isolation of some of these lactones, it is essential to remove all traces of $\mathrm{EtOH}$ from the solvent $\mathrm{CHCl}_{3}$.
\end{abstract}

Nearly 20 years ago, Joulain and Rouessac obtained the expected lactone $\mathbf{2}$ from the reaction of 4-nitroperbenzoic acid for 3 weeks on nopinone (1) [1], but had difficulty repeating the result [2]. Another publication claimed the isomeric lactone 3 as a by-product from the ozonolysis of $\beta$-pinene (5) [3]. Neither of these papers gave full spectral characterization of the products claimed.

Using 3-chloroperbenzoic acid (MCPBA) in $\mathrm{CHCl}_{3}$ from which the stabilizing ethanol had been removed, we obtained af ter 4 weeks at room temperature a 9:1 ratio of lactones $\mathbf{2}$ and $\mathbf{3}$ which were separated by flash chromatography and preparative gas chromatography. The structures were secured by NMR spectrometry. In particular, the major lactone $\mathbf{2}$ had the bridgehead $\mathrm{H}-\mathrm{C}(\mathrm{I})$ at $4.33 \mathrm{ppm}(d d, J=5$ and $5 \mathrm{~Hz})$, and the $\mathrm{CH}_{2}(4)$ group at 2.83 and $2.94 \mathrm{ppm}$. The ${ }^{\prime} \mathrm{H}$-NMR spectrum measured in $\mathrm{CCl}_{4}$ coresponded to the figures given by Joulain [1] The minor lactone 3 had a signal at $2.94 \mathrm{ppm}$ corresponding to the bridgehead $\mathrm{H}-\mathrm{C}(\mathrm{l})$, and the $\mathrm{CH}_{2}(4)$ at 4.32 and $4.70 \mathrm{ppm}$; when measured in the $\mathrm{CCl}_{4}$, the figures did not fit those given by the Japanese workers [3].

Methylnopinone (4), which is mostly the cis-isomer 4 a with ca. $12 \%$ of the transisomer $4 b$ [5], yielded the homologues 6 and $\mathbf{7}$ of $\mathbf{2}$ and $\mathbf{3}$, respectively, this time with $\mathbf{7}$ as the major isomer ( $c a .70 \%$ of the mixture). The ${ }^{1} \mathrm{H}-\mathrm{NMR}$ spectrum of the minor lactone 6 from this reaction had the bridgehead $\mathrm{H}-\mathrm{C}(1)$ at $4.33 \mathrm{ppm}$. $\mathrm{H}-\mathrm{C}(4)$ was at 2.96 $\mathrm{ppm}$, and coupled with the secondary $\mathrm{Me}$ group at $1.32 \mathrm{ppm}$. The major lactone 7 from the reaction had $\mathrm{H}-\mathrm{C}(1)$ at $2.935 \mathrm{ppm}$, and $\mathrm{H}-\mathrm{C}(4)$ at $4.97 \mathrm{ppm}$. Notable in the 'H-NMR of the lactones 3 and 7 was the position of the cis $\mathrm{H}-\mathrm{C}(5)$ at 2,49 and $2.15 \mathrm{ppm}$, respectively, the large shift to lower field being ascribed to the deshielding effect of the $\mathrm{C}=\mathrm{O}$ group. The attributions of the proton signals

*Correspondence: Dr. A.F. Thomas

Research Laboratories

Firmenich SA

$\mathrm{CH}-1211$ Genève 8 in the methyl-lactones 6 and 7 were also confirmed by NOE measurements. We were unable to separate completely the two lactones 8 and 9 arising from trans-methylnopinone (4b) except on a capillary GC column, but the similarity of their mass spectra to those of the cis-isomers 6 and 7 supported the structures. The NMR spectra will be discussed in the full paper.

If commercial $\mathrm{CHCl}_{3}$ was used in the reaction, the minor lactone 2 was not observed; neither was it observed when we tried to accelerate the reaction with $\mathrm{CF}_{3} \mathrm{COOH}$ [6]. Instead, we isolated the ester 10. The latter was readily identified from its mass and NMR spectra; in particular the disappearance of the doublet due to the cis-proton of the $\mathrm{CH}_{2}$ group in the pinane cyclobutane
Chimia 45 (1991) 164

() Schw'eiz. Cheniker-Verband; ISSN 0009-4293

ring, and replacement of the two separate signals for the two $\mathrm{CH}_{2}(4)$ signals of 3 (above) by a multiplet centred at $3.5 \cdot 7 \mathrm{ppm}$ associated with the $\mathrm{CH}_{2} \mathrm{OH}$ group.

The major lactone 2 from nopinone (1) was also converted to the corresponding cyclobutane esters by refluxing with alcohols. Thus, overnight boiling with $\mathrm{MeOH}$ yielded the ester 11, a compound that has been identified in the products of the ozonolysis of $\beta$-pinene (5) in $\mathrm{MeOH}$ [7]. This compound had the carbinol proton at 3.71 $\mathrm{ppm}$, and this was coupled with protons at 1.41 and $2.32 \mathrm{ppm}$ (the $\mathrm{CH}_{2}$ group of the cyclobutane ring), while the $\mathrm{CH}_{2}$ group adjacent to the COOMe group appeared as a triplet at $2.23 \mathrm{ppm}$.

Received: February 11, 1991

[l] D. Joulain, Thèse de docteur de 3ème cycle, Université Le Mans, October 1971; D. Joulain, F. Rouessac, C. R. Séances Acad. Sci., Sér. C $1971,273,561$.

[2] D. Joulain, personal communication.

[3] J. Tanaka, K. Takabe, M. Kawakita, M. lıo, T. Katagiri, Nippon Kagu Kuishi 1978, 284.

[4] Satisfactory analyses (elemental or exact mass measurement) were abtained for all substances. NMR spectral data (normally measured in $\mathrm{CDCl}_{3}$ ) were supported by $\mathrm{COSY}$, correlation, and occasionally NOE experiments. Structures were also confirmed by ${ }^{13} \mathrm{C}$-NMR spectra. Details will be given in the full paper.

[5] a) Y. Bessière-Chrétien, C. Grison, Bull. Soc. Chim. Fr. 1970, 3103; b) J. E. McMurry, J. H. Musser, M. S. Ahmad, L. C. Blaszczak, J. Org. Chem. 1975, 40, 1829.

[6] R. R. Sauers, R. W. Ubersax, J. Org. Chem. 1965, 30, 3939; S. S. C. Koch, A. R. Chamberlin, Synth. Commun. 1989, 19, 829.

[7] M. Ozainne (Firmenich SA), personal communication.

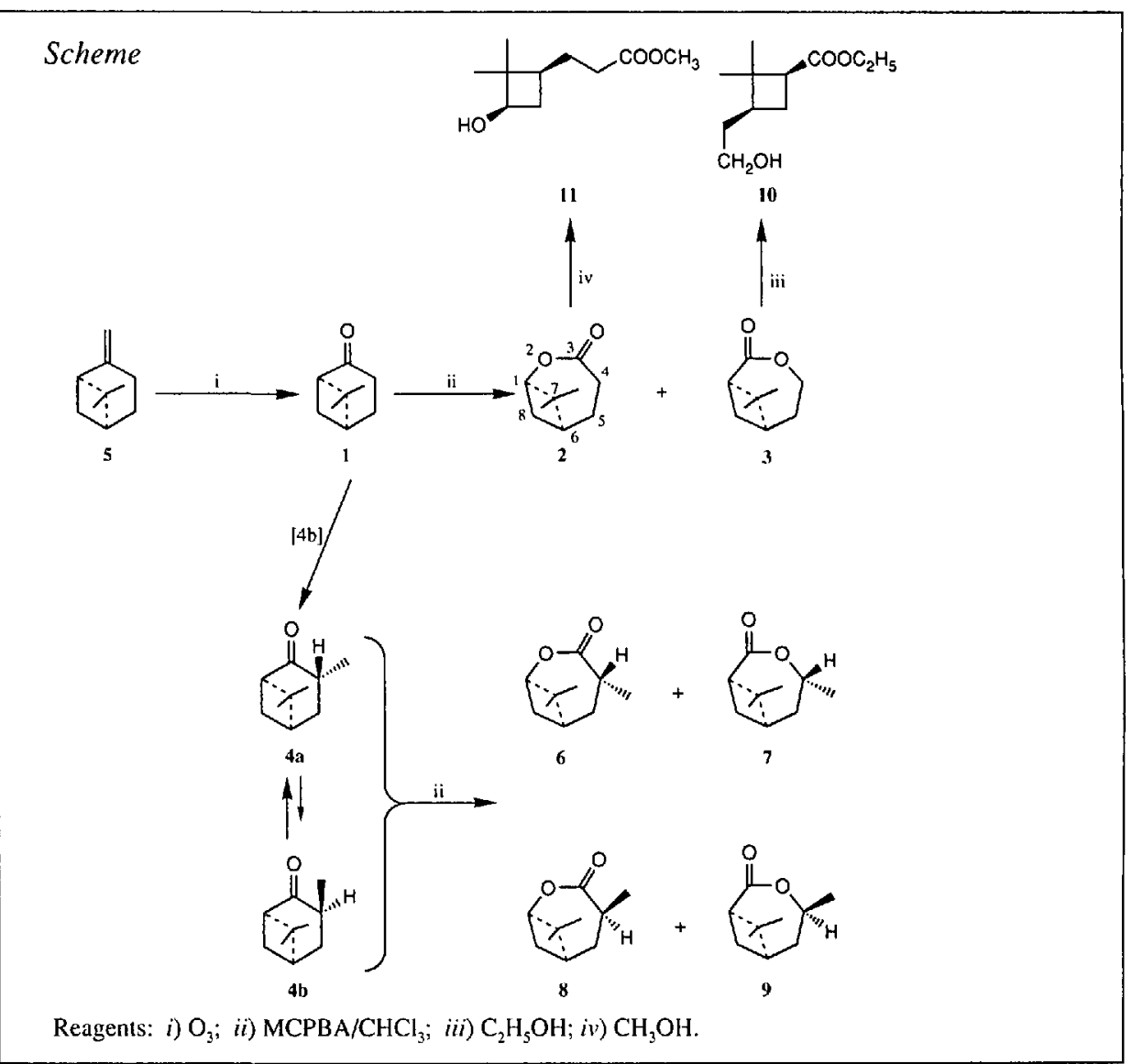

